\title{
Impaired exercise training-induced muscle fiber hypertrophy and Akt/mTOR pathway activation in hypoxemic patients with COPD
}

Citation for published version (APA):

Costes, F., Gosker, H. R., Feasson, L., Desgeorges, M., Kelders, M. C., Castells, J., Schols, A. M., \& Freyssenet, D. G. (2015). Impaired exercise training-induced muscle fiber hypertrophy and Akt/mTOR pathway activation in hypoxemic patients with COPD. Journal of Applied Physiology, 118(8), 1040-1049. https://doi.org/10.1152/japplphysiol.00557.2014

Document status and date:

Published: 15/04/2015

DOI:

10.1152/japplphysiol.00557.2014

Document Version:

Publisher's PDF, also known as Version of record

\section{Document license:}

Taverne

Please check the document version of this publication:

- A submitted manuscript is the version of the article upon submission and before peer-review. There can be important differences between the submitted version and the official published version of record.

People interested in the research are advised to contact the author for the final version of the publication, or visit the DOI to the publisher's website.

- The final author version and the galley proof are versions of the publication after peer review.

- The final published version features the final layout of the paper including the volume, issue and page numbers.

Link to publication

\footnotetext{
General rights rights.

- You may freely distribute the URL identifying the publication in the public portal. please follow below link for the End User Agreement:

www.umlib.nl/taverne-license

Take down policy

If you believe that this document breaches copyright please contact us at:

repository@maastrichtuniversity.nl

providing details and we will investigate your claim.
}

Copyright and moral rights for the publications made accessible in the public portal are retained by the authors and/or other copyright owners and it is a condition of accessing publications that users recognise and abide by the legal requirements associated with these

- Users may download and print one copy of any publication from the public portal for the purpose of private study or research.

- You may not further distribute the material or use it for any profit-making activity or commercial gain

If the publication is distributed under the terms of Article $25 \mathrm{fa}$ of the Dutch Copyright Act, indicated by the "Taverne" license above, 


\title{
Impaired exercise training-induced muscle fiber hypertrophy and Akt/mTOR pathway activation in hypoxemic patients with COPD
}

\author{
Frédéric Costes, ${ }^{1,2}$ Harry Gosker, ${ }^{3}$ Léonard Feasson, ${ }^{1,2}$ Marine Desgeorges, ${ }^{2}$ Marco Kelders, ${ }^{3}$ \\ Josiane Castells, ${ }^{2}$ Annemie Schols, ${ }^{3}$ and Damien Freyssenet ${ }^{2}$ \\ ${ }^{1}$ Service de Physiologie Clinique et de l'Exercice, Pôle NOL, CHU Saint Étienne, France; ${ }^{2}$ Laboratoire de Physiologie de \\ l'Exercice, Université de Lyon, Saint Étienne, France; and ${ }^{3}$ NUTRIM School for Nutrition, Toxicology and Metabolism, \\ Department of Respiratory Medicine, Maastricht University Medical Center, Maastricht, The Netherlands
}

Submitted 25 June 2014; accepted in final form 13 February 2015

Costes F, Gosker H, Feasson L, Desgeorges M, Kelders M, Castells J, Schols A, Freyssenet D. Impaired exercise training-induced muscle fiber hypertrophy and Akt/mTOR pathway activation in hypoxemic patients with COPD. J Appl Physiol 118: 1040-1049, 2015. First published February 20, 2015; doi:10.1152/japplphysiol.00557.2014.-Exercise training (ExTr) is largely used to improve functional capacity in patients with chronic obstructive pulmonary disease (COPD). However, ExTr only partially restores muscle function in patients with COPD, suggesting that confounding factors may limit the efficiency of ExTr. In the present study, we hypothesized that skeletal muscle adaptations triggered by ExTr could be compromised in hypoxemic patients with COPD. Vastus lateralis muscle biopsies were obtained from patients with COPD who were either normoxemic $\left(n=15\right.$, resting arterial $\mathrm{PO}_{2}=$ $68.5 \pm 1.5 \mathrm{mmHg})$ or hypoxemic $\left(n=8\right.$, resting arterial $\mathrm{Po}_{2}=57.0 \pm$ $1.0 \mathrm{mmHg}$ ) before and after a 2-mo ExTr program. ExTr induced a significant increase in exercise capacity both in normoxemic and hypoxemic patients with COPD. However, ExTr increased citrate synthase and lactate dehydrogenase enzyme activities only in skeletal muscle of normoxemic patients. Similarly, muscle fiber cross-sectional area and capillary-to-fiber ratio were increased only in patients who were normoxemic. Expression of atrogenes (MuRF1, MAFbx/ Atrogin-1) and autophagy-related genes (Beclin, LC3, Bnip, Gabarapl) remained unchanged in both groups. Phosphorylation of Akt (Ser473), GSK-3ß (Ser9), and p70S6k (Thr389) was nonsignificantly increased in normoxemic patients in response to ExTr, but it was significantly decreased in hypoxemic patients. We further showed on $\mathrm{C} 2 \mathrm{C} 12$ myotubes that hypoxia completely prevented insulin-like growth factor-1-induced phosphorylation of Akt, GSK-3 $\beta$, and p70S6K. Together, our observations suggest a role for hypoxemia in the adaptive response of skeletal muscle of patients with COPD in an ExTr program.

COPD; skeletal muscle; hypoxia; exercise training

CHRONIC OBSTRUCTIVE PULMONARY disease (COPD) is one of the main causes of morbidity and a leading cause of death worldwide (32). Muscle dysfunction is an important systemic consequence of COPD $(17,47)$. It is characterized by a shift from type I to type II muscle fibers, a loss of oxidative capacity, a reduced capillary density, and an atrophy of muscle fibers resulting in a severe loss of muscle mass (49). All these factors significantly contribute to reduce a patient's exercise capacity and quality of life, ultimately leading to greater mortality (5, 38). Although interventional strategies such as nutritional support and exercise training (ExTr) improve the quality of life and survival of patients with COPD when associated with a

Address for reprint requests and other correspondence: F. Costes, Service de Physiologie Clinique et de l'Exercice, CHU Saint Étienne, F42055 Saint Étienne Cedex 2 (e-mail: frederic.costes@chu-st-etienne.fr). weight gain $(29,39)$, these strategies do not succeed in counteracting muscle dysfunction and mass loss in patients.

Skeletal muscle mass is tightly regulated by the Akt/mammalian target of rapamycin (mTOR) pathway. Stimulation of the Akt/mTOR pathway increases protein translation in skeletal muscle $(7,36)$ and inhibits protein degradation via the inhibition of both ubiquitin-proteasome $(7,37,40)$ and autophagy-lysosome pathways $(26,50)$. This notably involves the regulation of FoxO1 and FoxO3 transcriptional activity on the promoters of MuRF1, Atrogin-1/MAFbx, and autophagy-related genes $(26,37,40,50)$. The available literature is conflicting regarding the regulation of this pathway in skeletal muscle of patients with COPD. A downregulation of the $\mathrm{Akt} / \mathrm{mTOR}$ pathway has been reported in skeletal muscle of patients with COPD compared with healthy subjects (45), whereas other studies reported no difference (30) or even an upregulation of the pathway (11). By contrast, a high-intensity interval training program allows the reactivation of the Akt/ mTOR pathway in skeletal muscle of patients with COPD (45). Furthermore, strength training in these patients increases muscle expression of insulin-like growth factor-1 (IGF-1), an upstream activator of the signaling pathway (24). Therefore, rehabilitation strategies incorporating resistance exercise may be helpful in limiting the extent of skeletal muscle mass loss in patients with COPD by activating the Akt/ mTOR pathway.

However, some recent studies suggest that the severity of hypoxemia could be associated with a resistance of skeletal muscle to the activation of the Akt/mTOR pathway. Indeed, muscle atrophy resulting from ambient hypoxia in rodents involves a downregulation of the Akt/mTOR pathway and an upregulation of the ubiquitin/proteasome pathway $(9,18)$. In line with these findings, we reported a downregulation of the Akt/mTOR pathway in hypoxemic patients with COPD compared with normoxemic patients with COPD (18). Taken together, these data strongly suggest that the response of Akt/mTOR pathway to ExTr could be compromised in hypoxemic patients with COPD.

In the present study, we therefore tested the hypothesis that the response of skeletal muscle to ExTr would be altered in patients with COPD and severe hypoxemia compared with normoxemic patients with COPD. We particularly focused our attention on the regulation of muscle fiber size and Akt/mTOR pathway. To further delineate the role of hypoxia, an in vitro analysis of the effects of hypoxia on the regulation of $\mathrm{Akt} / \mathrm{mTOR}$ pathway was also performed on C2C12 myotubes. 


\section{METHODS}

Subjects

We included 23 consecutive patients with COPD who entered an outpatient pulmonary rehabilitation center (CHU Saint Étienne). Written consent in accordance with the policy statement regarding the use of human subjects was obtained from all patients. This investigation was approved by the Rhône-Alpes Loire regional Consultant Committee on Human Protection for Medical Research and received agreement from the French Health Minister (DGS 2005/023). Criteria for inclusion in the study were a stable COPD disease (absence of exacerbation during the last $4 \mathrm{wk}$ ), the ability to perform maximal exercise testing, and no contraindication to muscle biopsy (e.g., chronic anticoagulant treatment). All patients were treated with inhaled long-lasting sympathomimetics and inhaled corticosteroids. Fifteen patients were also treated with tiotropium. None used oral corticosteroid regularly at the time of inclusion. Patients were considered to be hypoxemic (long-term oxygen therapy $>6 \mathrm{~h} /$ day for more than $3 \mathrm{mo}$, resting arterial $\mathrm{PO}_{2}<55 \mathrm{mmHg}$ at the initiation of the treatment, $n=8$ ) or normoxemic (resting arterial $\mathrm{Po}_{2}>60 \mathrm{mmHg}$, $n=15)$.

\section{Pulmonary Function and Morphometric Characteristics of Patients}

Lung volumes and airflows were measured (Bodybox; Medisoft, Dinant Belgium) according to European Respiratory Society recommendations (48). Postbronchodilator values were reported. Body composition was assessed by bioelectrical impedance at $50 \mathrm{~Hz}$ (Nutrigard Data Input; Pöcking, Germany) and fat free mass was calculated and compared with normal values according to those outlined by Kyle et al. (23). Body mass index (BMI) and fat-free mass index (FFMI) were also calculated.

\section{Evaluation of Exercise Capacity and Muscle Strength}

Incremental cycling exercise. After a 3-min warmup, the patients performed an incremental exercise test on a bicycle ergometer (5 to 10 W every min) while breathing room air (Ergocard; Medisoft, Dinant, Belgium). Breath-by-breath analysis of inspired and expired gases was used to determine oxygen consumption $\left(\dot{\mathrm{V}}_{2}\right), \mathrm{CO}_{2}$ output $\left(\dot{\mathrm{V}}_{\mathrm{CO}_{2}}\right)$, and minute ventilation $(\dot{\mathrm{V}} \mathrm{E})$. Peak power output $\left(\mathrm{W}_{\text {peak }}\right)$ corresponded to the highest workload that could be sustained for more than $20 \mathrm{~s}$. Electrocardiograhic and arterial oxygen saturation readings were monitored continuously. Arterialized blood samples from the ear were used for blood gas analysis and lactate measurement (ABL 800; Radiometer, Copenhagen, Denmark). A Borg scale was used to assess dyspnea and fatigue. Exercise capacity was determined before and after ExTr.

Maximal muscle force. Patients sat on a bench and performed isometric maximal voluntary contractions of the quadriceps muscle with a $90^{\circ}$ knee flexion while breathing room air. Muscle force was recorded with a dynamometer attached to the bench (Globus, Codognè, Italy). Handgrip strength was tested using a hand dynamometer (Jamar, Anaheim, CA). For each test, the best of three reproducible contractions $( \pm 10 \%)$ was recorded. Muscle strength was assessed before and after ExTr.

\section{Multidisciplinary Pulmonary Rehabilitation Program}

Patients participated in a multidisciplinary rehabilitation program consisting of 24 sessions (three sessions/week) under the supervision of a physiotherapist. ExTr included endurance bicycle exercise (20 to $30 \mathrm{~min}$ ) and treadmill exercise (10 to $15 \mathrm{~min}$ ). Patients were free to adapt resting periods as necessary. Exercise intensity was initially set to a heart rate corresponding to the ventilatory threshold (VT) measured during the initial maximal cycling test (42). When VT was not discernible (one patient in the hypoxemic group and two patients in the normoxemic group), the exercise intensity was arbitrarily fixed at
$60 \%$ of peak workload. Heart rate and oxygen saturation were monitored every $10 \mathrm{~min}$ during the session. Exercise intensity was adjusted every week to maintain heart rate to the target value: the workload was increased by $5 \mathrm{~W}$ when the heart rate decreased by more than 5 beats/min during two consecutive training sessions. For patients with severe hypoxemia, oxygen was administered during exercise to maintain $\mathrm{Sp}_{\mathrm{O} 2} \sim 90 \%$. Patients also performed resistance exercises of lower and upper limbs (three sets of 8-12 repetitions at $60 \%$ of their maximal isometric force). The workload was adjusted every week and the intensity was increased up to $85 \%$ of maximal force. Patients also participated in educational courses and relaxation sessions, and received dietary counseling. However, neither protein or essential amino acids supplementation nor hypocaloric diet was employed during the study.

\section{Vastus Lateralis Muscle Biopsy; Immunohistochemical and Biochemical Analyses}

Muscle biopsy. Biopsy of the vastus lateralis muscle was performed with a Weil-Blackesley forceps $24 \mathrm{~h}$ before the first training session and $24 \mathrm{~h}$ after the last training session. Patients with hypoxemia breathed ambient air for at least $1 \mathrm{~h}$ before the biopsy. Posttraining biopsy was taken $2 \mathrm{~cm}$ away from the pretraining biopsy site.

Immunohistology and morphological analysis. Muscle samples mounted in embedding medium were cut $(10 \mu \mathrm{m})$ in a cryostat microtome (HM 560; Microm, Walldorf, Germany) at $-20^{\circ} \mathrm{C}$. Sections were immunostained with antibodies against myosin heavy chain type I (A4.951; Alexis Biochemicals) and myosin heavy chain type IIa (N2.261; Alexis Biochemicals) as previously described (44). Fibers were classified as type I, IIa, I-IIa, or IIx fibers. The crosssectional area of at least 50 type I and type II fibers per biopsy was determined. Microvessels were identified using a CD31 antibody (Dako, Les Ulis, France). The number of capillaries in contact with each fiber was counted and expressed as the capillary-to-fiber ratio (19). Muscle sections were visualized under a light microscope (Eclipse E400; Nikon, Bashoevedorp, The Netherlands) connected to a digital camera (Nikon Coolpix 990). Photographs were analyzed using ImageJ software (http://rsb.info.nih.gov/ij/, 1997-2014; National Institutes of Health, Bethesda, MD).

RNA isolation, cDNA synthesis, and quantitative PCR analysis. Total RNA was phenol-extracted from $20-30 \mathrm{mg}$ of skeletal muscle samples conditioned in RNAlater (Qiagen, Courtaboeuf, France) using the Total RNA isolation kit (Ambion, Austin, TX) followed by purification on an RNeasy silica spin column (Qiagen). Complementary DNA was generated from $400 \mathrm{ng}$ of RNA using the Transcriptor First Strand cDNA synthesis kit (Roche Diagnostics, Mannheim, Germany). The selected forward and reverse primer sequences are listed in Table 1 . Real-time quantitative polymerase chain reaction (qPCR) was performed in a $20-\mu l$ final volume and optimized concentrations for each primer using Sensimix SYBR \& Fluorescein (GC Biotech, Alphen aan den Rijn, The Netherlands) and a MyiQ singlecolor real-time thermal cycler (Bio-Rad, Hercules, CA). Expression stability of seven reference genes (glyceraldehyde-3-phosphate dehydrogenase, $\beta$-actin, cyclophilin $\mathrm{A}$, large ribosomal protein ribosomal protein $\mathrm{P} 0$, large ribosomal protein, ribosomal protein 13A, $\beta 2-$ microglobulin, tyrosine 3-monooxygenase/tryptophan 5-monooxygenase activation protein zeta polypeptide) was assessed using GENORM software (Gent University, Gent, Belgium) (14, 43). All references genes were used for normalization.

Protein isolation. Muscle samples were homogenized at $4{ }^{\circ} \mathrm{C}$ in a 20-volume buffer consisting of $50 \mathrm{mM}$ Tris $\mathrm{HCl}(\mathrm{pH} 7.4), 100 \mathrm{mM}$ $\mathrm{NaCl}, 2 \mathrm{mM}$ EDTA, $2 \mathrm{mM}$ EGTA, $50 \mathrm{mM} \beta$-glycerophosphate, 50 $\mathrm{mM} \mathrm{NaF}, 1 \mathrm{mM}$ sodium orthovanadate, $120 \mathrm{nM}$ okadaic acid, and $1 \%$ Triton X-100. Homogenates were centrifuged at 12,000 $\mathrm{g}$ for $20 \mathrm{~min}$ at $4{ }^{\circ} \mathrm{C}$. Protein concentration of the supernatant was spectrophotometrically measured at $750 \mathrm{~nm}$ using the Bio-Rad protein assay (Marnes-la-Coquette, France). 
Table 1. Sequences of the primers used for real-time quantitative PCR analysis

\begin{tabular}{|c|c|c|}
\hline & Forward & Reverse \\
\hline Atrogin-1 & GAAGAAACTCTGCCAGTACCACTTC & CCCTTTGTCTGACAGAATTAATCG \\
\hline MuRF1 & GCGAGGTGGCCCCATT & GATGGTCTGCACACGGTCATT \\
\hline Gabarabl & ATCGGAAAAAGGAAGGAGAAAAGATC & CAGGCACCCTGGCTTTTGG \\
\hline Nedd4 & TCACTGGCACATCTCGGGTG & TCATAAGGTGGCAAGTCCAGGC \\
\hline MSTN & AACCTTCCCAGGACCAGGAGAA & TGTCTGTTACCTTGACCTCTAAAAACGG \\
\hline YWHAZ & ACTTTTGGTACATTGTGGCTTCAA & CCGCCAGGACAAACCAGTAT \\
\hline GAPDH & GCACCACCAACTGCTTAGCA & TGGCAGTGATGGCATGGA \\
\hline$\beta$-Actin & AAGCCACСCСАСТTCTCTCTAA & AATGCTATCACСTCCCCTGTGT \\
\hline Cyclophilin A & CATCTGCACTGCCAAGACTGA & TTCATGCCTTCTTTCACTTTGC \\
\hline RPLP0 & TCTACAACCCTGAAGTGCTTGATATC & GCAGACAGACACTGGCAACATT \\
\hline RPL13A & CCTGGAGGAGAAGAGGAAAGAGA & TTGAGGACCTCTGTGTATTTGTCAA \\
\hline $\mathrm{B} 2 \mathrm{M}$ & CTGTGCTCGCGCTACTCTCTCTT & TGAGTAAACCTGAATCTTTGGAGTACGC \\
\hline$\beta$-Actin & AGCAAGCAGGAGTACGATGAG & AACGCAGCTCAGTAACAGTC \\
\hline
\end{tabular}

LC3b, microtubule-associated protein light chain 3; MSTN, myostatin; BECN1, Beclin; Bnip3, BCL2/adenovirus E1B 19-kDa interacting protein; YWHAZ, tyrosine 3-monooxygenase/tryptophan 5-monooxygenase activation protein zeta polypeptide; GAPDH, glyceraldehyde-3-phosphate dehydrogenase; RPLPO, large ribosomal protein, ribosomal protein P0; RPL13A, large ribosomal protein, ribosomal protein 13A; B2M, beta-2 microglobulin.

Enzyme activities. Citrate synthase (CS, EC 4.1.3.7) and lactate dehydrogenase (LDH, EC 1.1.1.27) enzyme activities were fluorometrically determined $\left(\lambda_{\text {exc }}=340 \mathrm{~nm}\right.$ and $\left.\lambda_{\mathrm{em}}=450 \mathrm{~nm}\right)(13)$. Cathepsin B+L (EC 3.4.22.1 and EC 3.4.22.15), chymotrypsin-like (EC 3.4.21.1), trypsin-like (EC 3.4.21.4), and caspase-like (EC 3.4.13.17) enzyme activities of $20 \mathrm{~S}$ proteasome were fluorometrically measured $\left(\lambda_{\mathrm{exc}}=380 \mathrm{~nm}\right.$ and $\left.\lambda_{\mathrm{em}}=460 \mathrm{~nm}\right)$ by cleavage of specific amido-4-methylcoumarin-coupled substrates (Bachem, Weil am Rhein, Germany) as previously described $(6,12)$.

Western immunoblotting. Proteins $(50 \mu \mathrm{g})$ were separated on $12.5 \%$ SDS-PAGE and transferred onto $0.45-\mu \mathrm{m}$ nitrocellulose membranes. Gel loading was systematically checked by Coomassie staining. Immunoblot analysis of proteins was performed as previously described (21) with the following primary antibodies against Akt $(1: 1,000)$ : $\mathrm{Akt}^{\mathrm{Ser} 473}(1: 1,000)$, glycogen synthase kinase (GSK)-3 $\beta(1: 1,000)$, GSK-3 $\beta^{\text {Ser9 }}(1: 1,000)$, p $70^{\text {S6K }}(1: 1,000)$, and p70 ${ }^{\text {S6KThr389 }}(1: 1,000)$. All primary antibodies were obtained from Millipore (Molsheim, France).

\section{In Vitro Study}

Cell culture. C2C12 myoblasts (CRL-1772; American Type Culture Collection) were cultured in Dulbecco's modified Eagle's medium (DMEM) supplemented with $10 \%$ fetal bovine serum and $1 \%$ penicillin/streptomycin $(\mathrm{P} / \mathrm{S})$ at $37^{\circ} \mathrm{C}$ in $5 \% \mathrm{CO}_{2}$ in air on $60-\mathrm{mm}$ dishes. At $70 \%$ confluence, myoblasts were differentiated into myotubes in DMEM supplemented with $5 \%$ horse serum and $1 \% \mathrm{P} / \mathrm{S}$. After 5 days of differentiation, myotubes were exposed to hypoxia $\left(2 \% \mathrm{O}_{2}\right.$ in $\left.5 \% \mathrm{CO}_{2}\right)$ or normoxia $\left(21 \% \mathrm{O}_{2}\right.$ in $\left.5 \% \mathrm{CO}_{2}\right)$ for $48 \mathrm{~h}$. Two days later, myotubes were cultured in DMEM containing $1 \% \mathrm{P} / \mathrm{S}$ for $4 \mathrm{~h}$ in hypoxia or normoxia. IGF-1 (20 nM) was then added (SigmaAldrich, Saint-Quentin Fallavier, France) and the myotubes were replaced in their respective ambiance before being harvested at the indicated time points.

RNA isolation, cDNA synthesis, and qPCR analysis. Myotubes were harvested 120 and $180 \mathrm{~min}$ after IGF-1 addition and used for total RNA extraction (RNeasy mini kit; Qiagen) following the manufacturer's instructions. Myotubes without IGF-1 were used as the control (0 min). Total RNA extraction, synthesis of cDNA, and real-time PCR were performed as previously described (10). The selected forward and reverse primer sequences are listed in Table 1. Reference genes ( $\beta$-actin and $\alpha$-tubulin) were used to normalize the expression level of genes of interest $(14,43)$.

Protein extraction and luminex analysis. Myotubes were harvested 60 and $180 \mathrm{~min}$ after IGF-1 addition. Myotubes without IGF-1 were used as the control $(0 \mathrm{~min})$. Soluble proteins were extracted and analyzed for the expression of phosphorylated forms of $\mathrm{Akt}^{\mathrm{Ser} 473}$, GSK-3 $\beta^{\text {Ser9 } 9}$, and $\mathrm{p} 70^{\text {S6KThr421/Ser424 }}$ (Bio-Rad). The analysis consisted of a double-laser fluorescence detection, which allowed simultaneous identification of the target protein through the red fluorescence emission signal of the bead and quantification of the target protein through the fluorescence intensity of phycoerythrin (Bio-Plex 200 System; Bio-Rad) (10).

\section{Statistical Analysis}

The clinical outcome initially designed for the present study was a training effect on maximal power output. We performed a statistical power of analysis and calculated that eight patients in each group was enough to detect a $10-\mathrm{W}$ difference in peak workload with a standard deviation of $6 \mathrm{~W}(\alpha=0.05, \beta=90 \%)$. Data are means \pm SE. The effect of ExTr and hypoxemia on exercise capacity, muscle strength, protein content, and mRNA level was assessed by two-way ANOVA (Statview 5.0) followed by a Scheffé protected least significance difference test to detect specific mean differences. Akt, GSK-3 $\beta$, and $\mathrm{p} 70^{\mathrm{S} 6 \mathrm{~K}}$ phosphorylation levels between normoxemic and hypoxemic patients were compared by a Mann-Whitney test. For in vitro experiments, mRNA and phosphorylated proteins levels were compared by two-way ANOVA (time $X$ ambiance) followed by a Scheffé post hoc test. Statistical difference was established at $P<0.05$.

\section{RESULTS}

\section{Baseline Patient Characteristics and Functional Benefits of ExTr}

Patients displayed moderate to severe airway obstruction and mild to moderate lung hyperinflation (Table 2). Hypox- 
Table 2. Baseline morphometric, spirometric and blood gases characteristics in normoxemic and hypoxemic patients with COPD

\begin{tabular}{lcc}
\hline \hline Subject Characteristic & Normoxemic Group & Hypoxemic Group \\
\hline$n$, sex ratio & $15,12 \mathrm{M} / 3 \mathrm{~F}$ & $8,8 \mathrm{M}$ \\
Age, yr & $60.5 \pm 1.9$ & $60.4 \pm 2.4$ \\
Gold stage II/III/IV & $4 / 9 / 2$ & $0 / 0 / 8$ \\
FEV $_{1}$, liter & $1.18 \pm 0.07$ & $1.05 \pm 0.13$ \\
FEV,$\%$ pred & $42 \pm 3$ & $34 \pm 4$ \\
FVC, liter & $2.85 \pm 0.22$ & $3.35 \pm 0.23$ \\
FVC, \% pred & $77 \pm 7$ & $87 \pm 6$ \\
FEV $/$ FVC, $\%$ & $43 \pm 3$ & $31 \pm 3$ \\
$\mathrm{RV}$, liter & $4.12 \pm 0.32$ & $5.10 \pm 0.50$ \\
$\mathrm{RV}, \%$ pred & $186 \pm 12$ & $224 \pm 22$ \\
$\mathrm{TLC}$, liter & $7.20 \pm 0.47$ & $8.51 \pm 0.58$ \\
$\mathrm{TLC}_{\text {\% }} \%$ pred & $112 \pm 10$ & $131 \pm 6$ \\
$\mathrm{PaO}_{2}$, mmHg & $68.5 \pm 1.5$ & $57.0 \pm 1.0^{\mathrm{a}}$ \\
$\mathrm{PaCO}_{2}$, mmHg & $35.9 \pm 1.2$ & $36.9 \pm 1.8$ \\
$\mathrm{SaO}_{2}, \%$ & $95.1 \pm 0.4$ & $90.9 \pm 0.8$ \\
\hline
\end{tabular}

COPD, chronic obstructive pulmonary disease; $\mathrm{FEV}_{1}$, forced expiratory volume in $1 \mathrm{~s}$; \% pred, percentage of predicted value; FVC, forced vital capacity; RV, residual volume; TLC, total lung capacity; $\mathrm{PaO}_{2}$, oxygen arterial blood pressure; $\mathrm{Pa}_{\mathrm{CO}_{2}}$, carbon dioxide arterial blood pressure; $\mathrm{SaO}_{2}$, oxygen arterial saturation. Data are means $\pm \mathrm{SE}$. aSignificantly different from corresponding normoxemic patients.

emic patients had a lower $\mathrm{Pa}_{\mathrm{O}_{2}}$ and a tendency toward more severe airway obstruction and higher hyperinflation (Table 2). BMI and FFMI were similar in both normoxemic and hypoxemic groups (Table 3). A depleted state (FFMI $<17$ for men, $15 \mathrm{~kg} / \mathrm{m}^{2}$ for women) was present in five normoxemic patients and four hypoxemic patients.

Before ExTr, hypoxemic patients had a lower $\mathrm{W}_{\text {peak }}$ (Table 3 ). $\dot{\mathrm{V}}_{2}$ peak also tended to be lower in patients with hypoxemia. Relative training intensities at the end of the first month of the training program were similar in both groups $(76.5 \pm 7.7 \%$ and $66.2 \pm 11.6 \%$ of pretraining $\mathrm{W}_{\text {peak }}$ in normoxemic and hypoxemic patients, respectively). At the end of the training program, training intensities were similar in normoxemic and hypoxemic patients $\left(83.6 \pm 7 \%\right.$ vs. $76.5 \pm 7 \%$ of pretraining $\mathrm{W}_{\text {peak }}$ for normoxemic and hypoxemic groups, respectively). Duration of the training sessions was also similar in normoxemic and hypoxemic patients $(36 \pm 3$ vs. $30 \pm 2 \mathrm{~min}$, and $36 \pm 3$ vs. $33 \pm 1$ min for normoxemic and hypoxemic groups, respectively, at the end of the first and second month of ExTr). ExTr significantly increased $\mathrm{W}_{\text {peak }}$, illustrating the efficacy of the rehabilitation program (Table 3). The relative increase in $\mathrm{W}_{\text {peak }}$ was not significantly different between groups. $\dot{\mathrm{V}}_{2}$ peak tended to increase, but it did not reach the significance level. The $\mathrm{V}_{2}$ /workload relationship was not significantly different between groups and did not change after ExTr $(10.1 \pm 0.7$ and $11.2 \pm 1.5 \mathrm{ml} \cdot \mathrm{min}^{-1} \cdot \mathrm{W}^{-1}$ in normoxemic and hypoxemic groups, respectively). Dyspnea and fatigue Borg scores were similar in both groups of patients during incremental cycling exercise before and after ExTr (Table 3). Quadriceps muscle force increased significantly in response to ExTr both in normoxemic and hypoxemic patients (Table 3 ). Finally, handgrip force, used as a control test, remained unchanged in response to ExTr.

\section{Effects of ExTr on CS and LDH Activities, Muscle Fiber Type Distribution, Muscle Fiber Size, and Capillarization}

CS activity was significantly increased in the normoxemic group in response to ExTr, whereas it remained relatively unchanged in the hypoxemic group (Fig. 1A). LDH activity, which was significantly higher in hypoxemic patients before ExTr, was increased only in normoxemic patients in response to $\operatorname{ExTr}($ Fig. $1 B)$.

Muscle fiber type distribution was not significantly different between groups before ExTr, and it remained unchanged in response to ExTr (Table 4). Muscle fiber cross-sectional area was significantly larger in hypoxemic patients compared with normoxemic patients before ExTr (Fig. 2). ExTr elicited a significant increase in muscle fiber cross-sectional area in the normoxemic group, whereas muscle fiber cross-sectional area remained unchanged in hypoxemic patients (Fig. 2). Before training, the capillary-to-fiber ratio was significantly higher in the hypoxemic group compared with that in the normoxemic group. Capillary-to-fiber ratio increased significantly in the normoxemic group with ExTr, whereas it remained unchanged in the hypoxemic group (Table 4). Normalized to muscle fiber

Table 3. Body composition and exercise tolerance in normoxemic and hypoxemic patients with COPD before and after exercise training

\begin{tabular}{|c|c|c|c|c|}
\hline & \multicolumn{2}{|c|}{ Before ExTr } & \multicolumn{2}{|c|}{ After ExTr } \\
\hline BMI, $\mathrm{kg} / \mathrm{m}^{2}$ & $23.8 \pm 1.1$ & $23.0 \pm 1.6$ & $24.1 \pm 1.0$ & $23.0 \pm 1.5$ \\
\hline $\mathrm{W}_{\text {peak }}, \mathrm{W}$ & $63.7 \pm 6.7$ & $43.1 \pm 4.3$ & $72.0 \pm 8.7$ & $52.5 \pm 3.0$ \\
\hline $\mathrm{W}_{\text {peak }}, \%$ pred & $41 \pm 4$ & $26 \pm 3^{\mathrm{a}}$ & $45 \pm 5^{\mathrm{b}}$ & $32 \pm 3^{\mathrm{ab}}$ \\
\hline$\dot{\mathrm{V}} \mathrm{O}_{2 \text { peak }}, \mathrm{ml} / \mathrm{min}$ & $933 \pm 75$ & $816 \pm 81$ & $989 \pm 89$ & $864 \pm 60$ \\
\hline$\dot{\mathrm{V}}_{\mathrm{O}_{2 \text { peak }}, \% \text { pred }}$ & $51 \pm 4$ & $41 \pm 4$ & $52 \pm 4$ & $45 \pm 7$ \\
\hline Dyspnea Borg score & $6.4 \pm 0.5$ & $5.9 \pm 0.7$ & $6.4 \pm 0.7$ & $6.8 \pm 0.7$ \\
\hline Fatigue Borg score & $5.0 \pm 0.7$ & $6.5 \pm 0.7$ & $4.4 \pm 0.6$ & $5.9 \pm 0.46$ \\
\hline QMF, N & $329 \pm 27$ & $309 \pm 29$ & $392 \pm 28^{b}$ & $401 \pm 50^{\mathrm{b}}$ \\
\hline Handgrip, $\mathrm{N}$ & $359 \pm 21$ & $388 \pm 27$ & $395 \pm 28$ & $407 \pm 34$ \\
\hline
\end{tabular}

BMI, body mass index; ExTr, exercise training; FFMI, fat-free mass index; W, power output; $\dot{\mathrm{V}}_{2}$, oxygen uptake; HR, peak heart rate expressed as a percentage of predicted value; VR, ventilatory reserve calculated as (MVV - $\left.\dot{V}_{E_{\max }}\right) / \mathrm{MVV}\left(\mathrm{MVV}\right.$ was predicted as $\left.35 \times \mathrm{FEV}_{1}\right)$; dyspnea and fatigue Borg

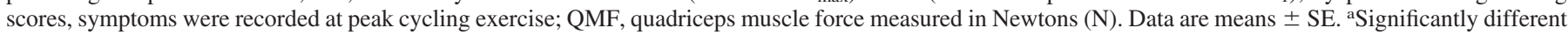

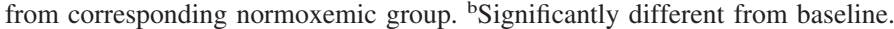




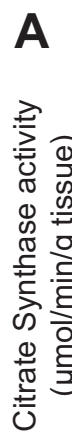

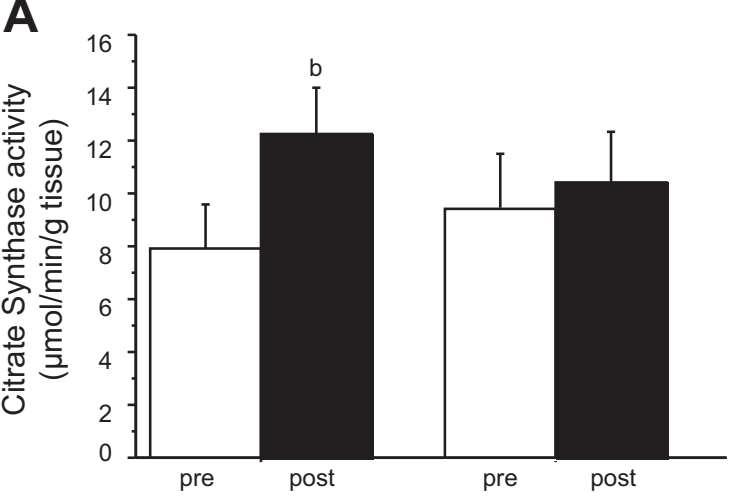

Normoxemic group

B

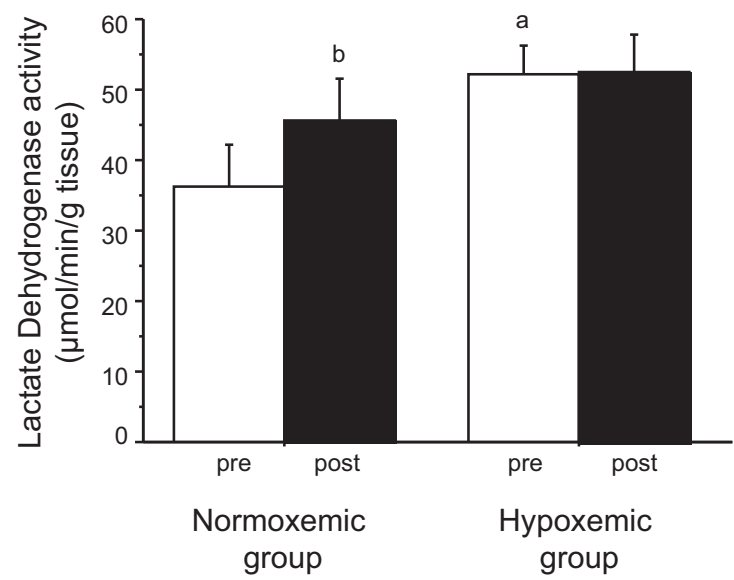

Fig. 1. Citrate synthase $(A)$ and lactate dehydrogenase $(B)$ enzyme activities in vastus lateralis muscle in normoxemic and hypoxemic patients with chronic obstructive pulmonary disease (COPD) before and after exercise training

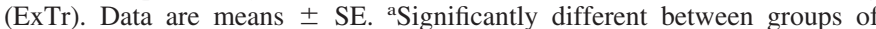

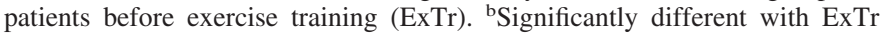
within a group of patients.

cross-sectional area, capillary-to-fiber ratio was nonsignificantly increased in the normoxemic group (Table 4).

\section{Ubiquitin-Proteasome and Autophagy-Lysosome Pathways}

We first determined whether some critical players in the proteolytic pathways were differentially regulated between normoxemic and hypoxemic patients with COPD. Messenger

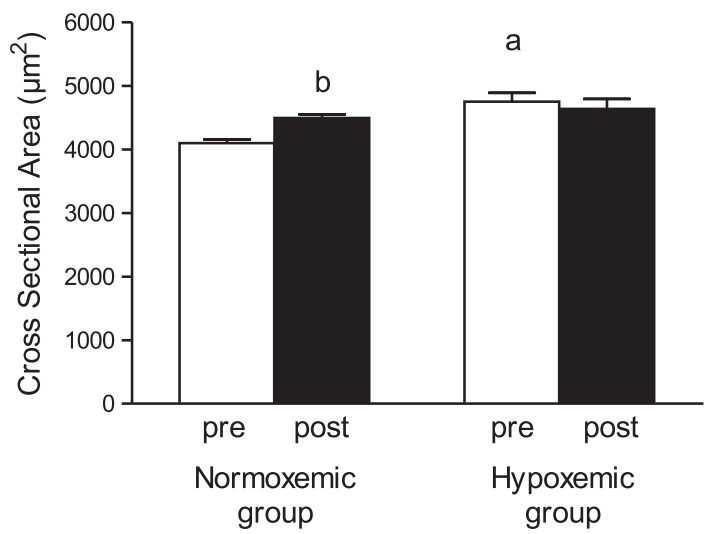

Fig. 2. Vastus lateralis muscle fiber cross-sectional area in normoxemic and hypoxemic patients with COPD before and after ExTr. Data are means \pm SE. ${ }^{a}$ Significantly different between groups of patients pre ExTr. ${ }^{\mathrm{b}}$ Significantly different with ExTr within a group of patients.

RNA levels of MuRF1, Atrogin-1, and Nedd4 were not different between groups before or after ExTr (Fig. 3A). In agreement with these data, chymotrypsin-like enzyme activity of 20S proteasome remained unchanged with ExTr in both groups (Fig. 3B). Similarly, mRNA levels of autophagy-related genes (Beclin, LC3, Bnip, Gabarapl), as well as cathepsin $\mathrm{B}+\mathrm{L}$ enzyme activity, were similar in both groups and did not change after ExTr (Fig. 3, $C$ and $D$ ). Finally, the plasma level of procatabolic (IL-1 $\beta$, IL-6, IL-8, TNF- $\alpha$, IFN- $\gamma$ ) and anticatabolic (IL-10, IL-15) cytokines did not differ between groups and remained unchanged with ExTr (data not shown).

\section{Impaired Akt/mTOR Pathway Activation by ExTr in Hypoxemic Patients with COPD}

We next determined whether expression of known regulators of the Akt/mTOR pathway was differentially regulated in response to ExTr between normoxemic and hypoxemic patients. The transcript level of IGF-1, a positive regulator of the Akt/mTOR pathway (36), and myostatin, a negative regulator of the Akt/mTOR pathway (3), did not differ between normoxemic and hypoxemic patients with COPD before or after ExTr (Fig. 4, $A$ and $B$ ).

We next investigated the phosphorylation status of several downstream mediators of the Akt/mTOR pathway. The phosphorylation levels of $\mathrm{Akt}^{\mathrm{Ser} 473}, \mathrm{GSK}-3 \beta^{\text {Ser9 }}$, and $\mathrm{p} 70^{\text {S6kThr389 }}$ were differentially regulated in response to ExTr between normoxemic and hypoxemic patients. The relative changes in the phosphorylation level of these proteins were decreased in

Table 4. Vastus lateralis muscle fiber type distribution and capillarization in normoxemic and hypoxemic patients with COPD before and after exercise training

\begin{tabular}{|c|c|c|c|c|}
\hline & \multicolumn{2}{|c|}{ Before ExTr } & \multicolumn{2}{|c|}{ After ExTr } \\
\hline Type I, \% & $20.8 \pm 6.3$ & $17.6 \pm 4.9$ & $28.6 \pm 4.5$ & $19.3 \pm 3.1$ \\
\hline Type IIa, \% & $69.9 \pm 5.0$ & $68.2 \pm 4.8$ & $59.5 \pm 5.4$ & $67.6 \pm 3.3$ \\
\hline Type IIx, \% & $4.2 \pm 2.1$ & $6.9 \pm 2.7$ & $10.9 \pm 6.7$ & $9.9 \pm 3.9$ \\
\hline Capillary-to-fiber ratio & $2.76 \pm 0.05$ & $2.95 \pm 0.06^{\mathrm{a}}$ & $3.20 \pm 0.06^{\mathrm{b}}$ & $2.91 \pm 0.06^{\mathrm{a}}$ \\
\hline $\mathrm{CF} / \mathrm{CSA}$ & $1.35 \pm 0.14$ & $1.43 \pm 0.20$ & $2.08 \pm 0.70$ & $1.16 \pm 0.09$ \\
\hline
\end{tabular}

$\mathrm{CF} / \mathrm{CSA}$, capillary-to-fiber ratio corrected to fiber cross-sectional area. Data are means \pm SE. aSignificantly different from corresponding normoxemic group.

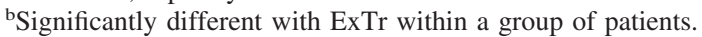


A

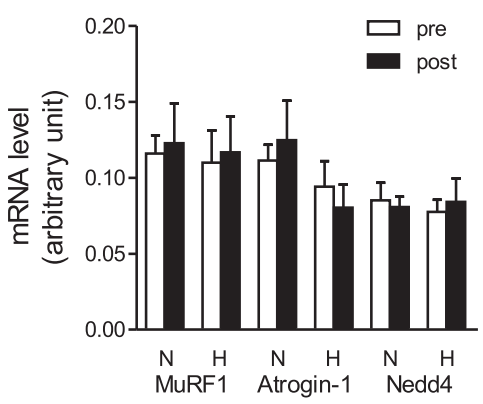

B

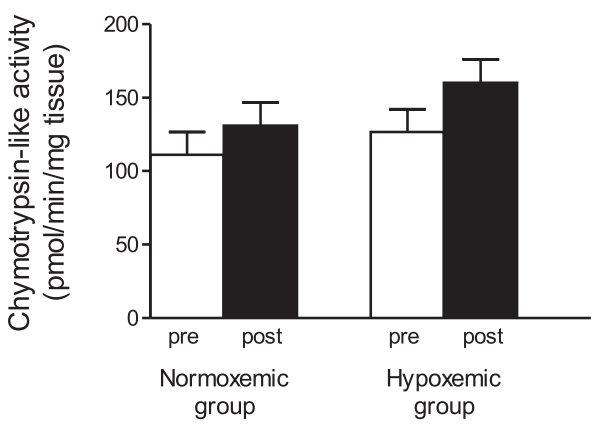

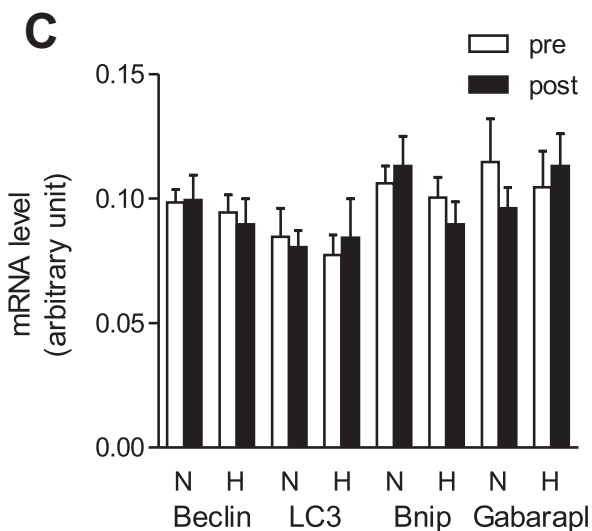

D

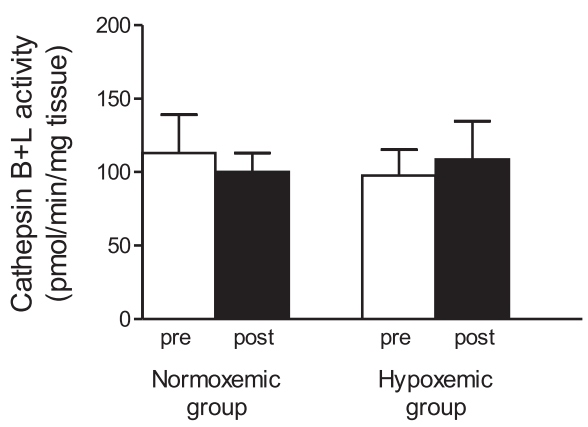

Fig. 3. Ubiquitin-proteasome and autophagylysosome pathways. A: messenger RNA level of ubiquitin ligases MuRF1, Atrogin-1, and Nedd4 in the vastus lateralis muscle of normoxemic $(\mathrm{N})$ and hypoxemic $(\mathrm{H})$ patients with COPD before (open bars) and after (black bars) ExTr. B: chymotrypsin-like enzyme activity in the vastus lateralis muscle before (open bars) and after (black bars) ExTr. $C$ : messenger RNA level of autophagy-related genes [Beclin, microtubule-associated protein light chain 3 (LC3), BCL2/adenovirus E1B $19-\mathrm{kDa}$ interacting protein (Bnip), and Gabarapl]. $D$ : cathepsin $\mathrm{B}+\mathrm{L}$ enzyme activity in vastus lateralis muscle of $\mathrm{N}$ and $\mathrm{H}$ patients with COPD before (open bars) and after (black bars) ExTr. Messenger RNA level was determined by relative quantification with real-time PCR. Data are means \pm SE. hypoxemic patients with COPD in response to ExTr. Total protein content of Akt, GSK-3 $\beta$, and $\mathrm{p} 70^{\mathrm{S} 6 \mathrm{k}}$ did not differ between groups and remained unchanged with ExTr (data not shown).

\section{Hypoxia Abolished IGF-1-Induced Stimulation of the Akt/ mTOR Pathway in C2C12 Myotubes}

These data suggest that hypoxemia could be a factor that contributes to limiting the capacity of the Akt/mTOR pathway to respond to ExTr. We therefore further tested this hypothesis by determining in vitro whether culturing myotubes in hypoxia for $48 \mathrm{~h}$ could limit or blunt stimulation of the Akt/mTOR pathway induced by IGF-1. When cultured in normoxia, addition of IGF-1 induced an immediate and sustained increase in the phosphorylation of Akt, GSK-3 $\beta$, and p70S6K (Fig. 5A). By contrast, hypoxia completely prevented IGF-1-induced phosphorylation of Akt and GSK-3 $\beta$. Phosphorylation of p70S6K was also decreased in response to IGF-1 addition in hypoxia-preconditioned myotubes. Finally, the transcript level of MuRF1 decreased significantly $180 \mathrm{~min}$ after IGF-1 addition, whereas the variation in the level of Atrogin-1 did not reach statistical significance (Fig. 5B). No difference was observed between culture conditions.

\section{DISCUSSION}

In the present study, we have demonstrated that ExTr induced similar functional benefits in exercise capacity in normoxemic and hypoxemic patients. However, our biochemical analyses indicated that muscle fiber hypertrophy and activation of the Akt/mTOR pathway by ExTr was impaired in the skeletal muscle of hypoxemic patients with COPD. Furthermore, in vitro analysis using $\mathrm{C} 2 \mathrm{C} 12$ myotubes indicated that hypoxia prevented activation of the Akt/mTOR pathway in response to IGF-1 addition, suggesting that hypoxemia could be a factor that contributes to limiting the extent of skeletal muscle response to ExTr in hypoxemic patients with COPD.

The training program was effective at increasing maximal power output in both groups of patients. The extent of improvement was of comparable amplitude to that previously described in patients with moderate to severe COPD (34) and exceeded the minimal perceived difference (31). These data confirmed that ExTr can similarly improve the exercise capacity of normoxemic and hypoxemic patients with COPD $(2,8)$. Such an observation has been also reported in cachectic and noncachectic patients with COPD in response to pulmonary rehabilitation (45). Exercise tolerance is influenced by many factors, including motivation and habituation to the exercise test. After ExTr, desensitization to dyspnea also contributes to the improved exercise tolerance due to the alleviation of the discomfort of breathing $(1,4)$. That this phenomenon could occur in the hypoxemic group in the present study during submaximal exercise could explain their better exercise tolerance and greater sustained workload without the need for peripheral adaptations.

The increase in CS and LDH activities in response to ExTr in skeletal muscle of normoxemic patients with COPD strongly suggests an increase in their overall capacity to produce ATP during exercise by increasing both oxidative and anaerobic metabolic capacities. ExTr was thus efficient in eliciting metabolic adaptations in skeletal muscle of normoxemic patients. By contrast, skeletal muscle of hypoxemic patients seems to be refractory, in that both CS and LDH activities remained unchanged in response to ExTr. This is in agreement with previous reports showing that chronic exposure to hypoxia did 

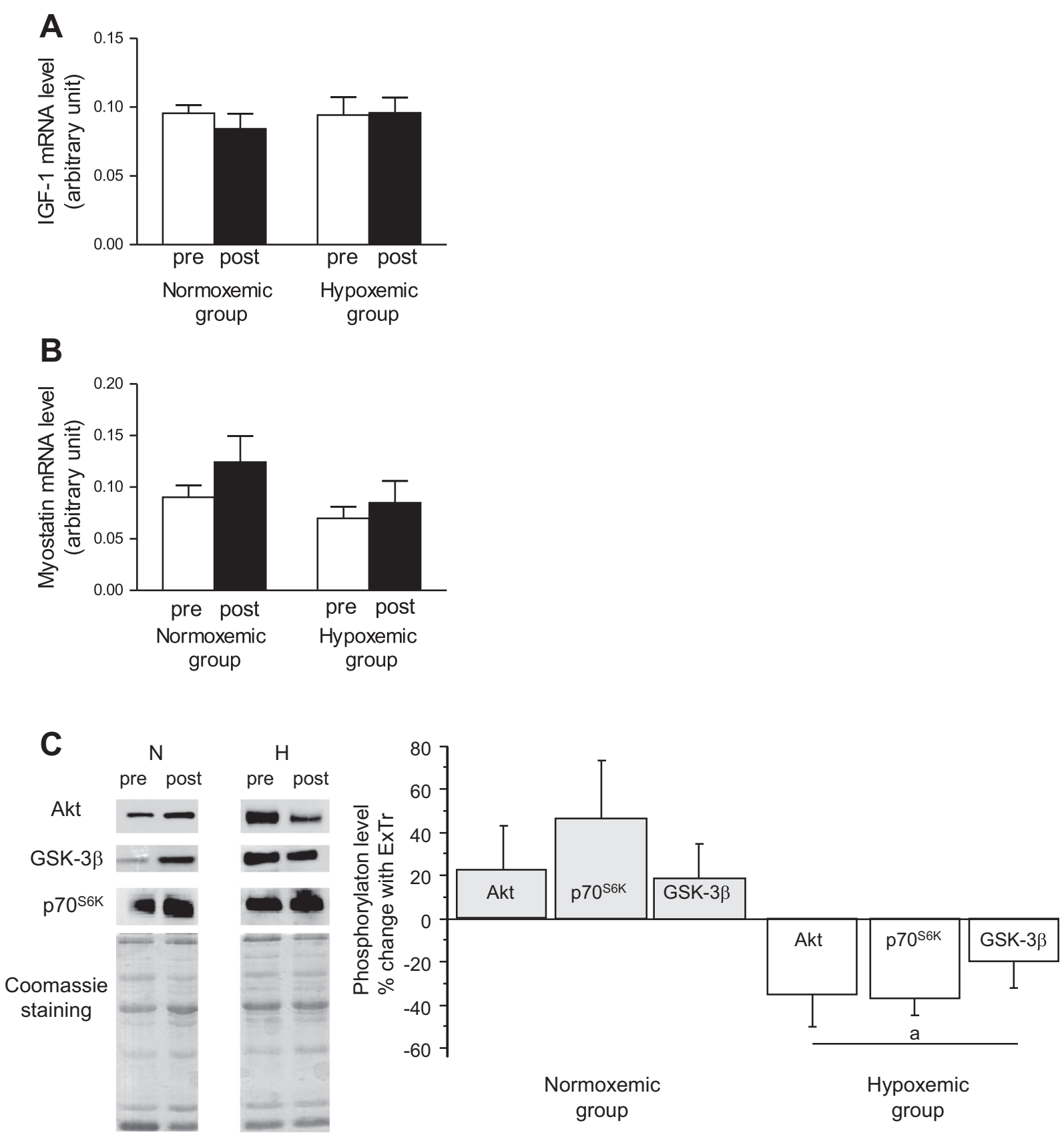

Fig. 4. Insulin-like growth factor (IGF)-1 mRNA level, myostatin mRNA level, and the Akt/mTOR pathway. IGF-1 (A) and myostatin (B) mRNA levels remained unchanged in the vastus lateralis muscle of normoxemic and hypoxemic patients with COPD before (open bars) and after (black bars) ExTr. Messenger RNA level was determined by relative quantification with real-time PCR. C: relative changes in phosphorylation levels of Akt ${ }^{\mathrm{Ser} 473}$, GSK-3 $\beta^{\mathrm{Ser} 9}$, and p70 ${ }^{\mathrm{S} 6 \mathrm{KThr} 421 / \mathrm{Ser} 424}$ in response to ExTr in normoxemic and hypoxemic patients. Representative blots before and after ExTr for each phosphorylated protein measured appear on the

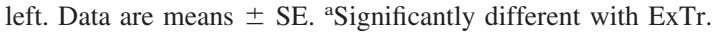

not change (or even decreased) mitochondrial enzyme activity $(27,35)$ and mitochondrial content of skeletal muscle (20). Overall, this suggests that the extent of skeletal muscle metabolic response to ExTr is altered in hypoxemic patients with COPD.

Surprisingly, hypoxemic patients with COPD had larger fiber cross-sectional area compared with normoxemic patients. This difference still existed when female patients from the normoxic group were excluded from the analysis, thus ruling out a gender effect. A lower muscle fiber size in normoxemic patients with COPD compared with those who were hypoxemic before ExTr could have been beneficial by increasing the capillary-to-muscle fiber ratio and thus improving oxygen delivery to skeletal muscle (15). However, the observation that the capillary-to-fiber ratio normalized to muscle fiber crosssectional area was not different between groups does not support this hypothesis. The reported increase in muscle fiber cross-sectional area with ExTr in normoxemic patients is in agreement with a recent study showing that ExTr in normoxemic patients with COPD increased muscle fiber cross-sec- 
A
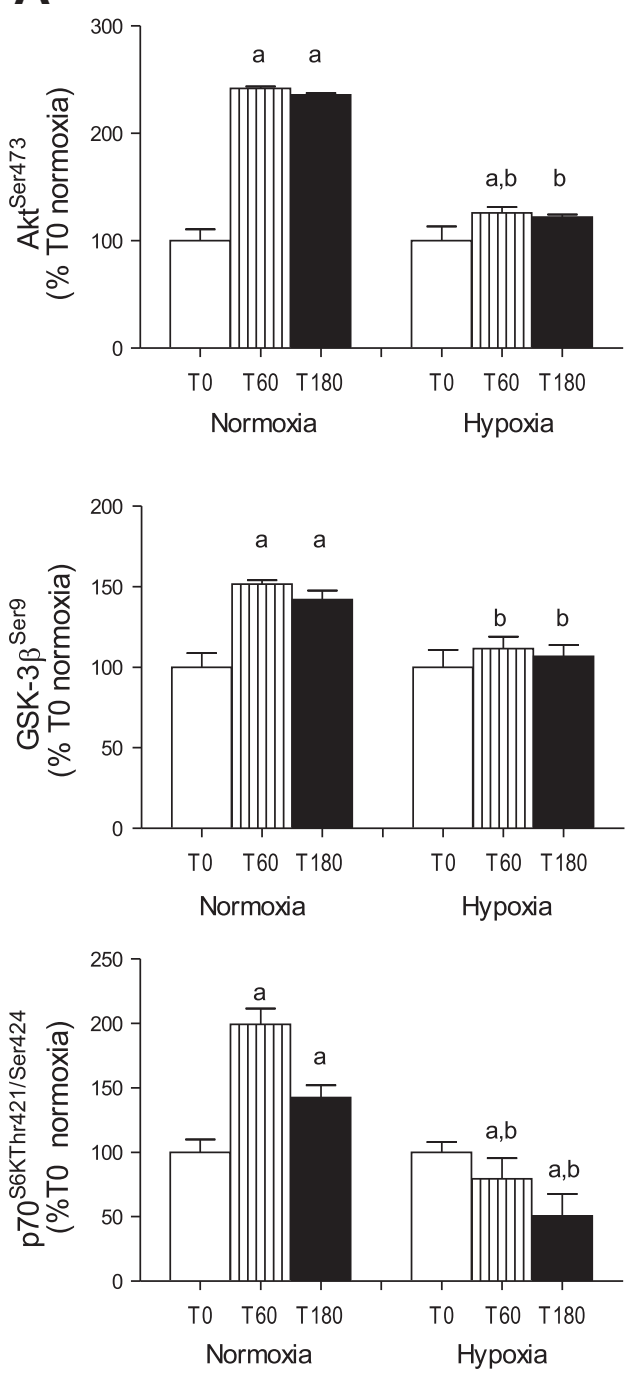

B
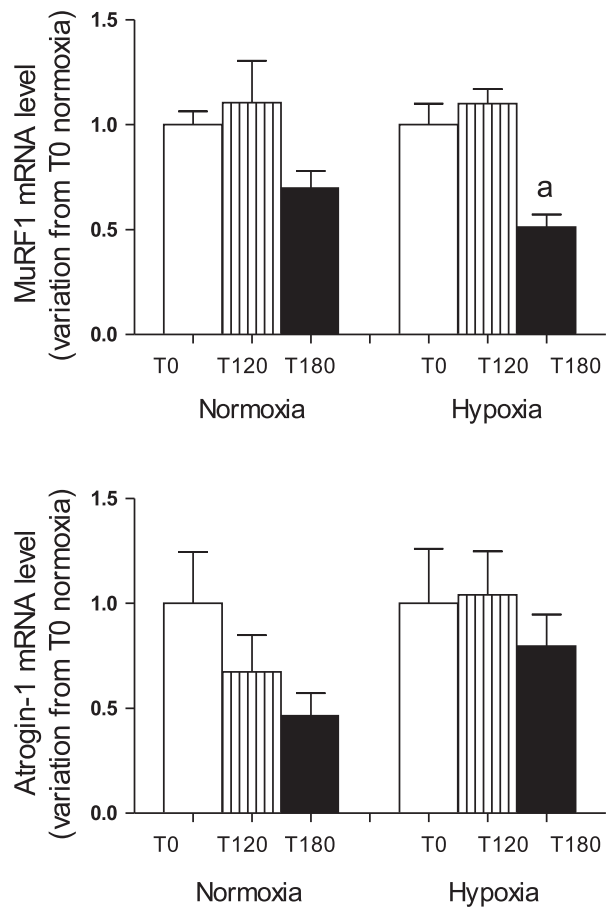

Fig. 5. Effects of hypoxia on phosphorylation levels of $\mathrm{Akt}^{\mathrm{Ser} 473}$, GSK-3 $\beta^{\text {Ser9 }}$, and p70 6 KThr421/Ser424 $(A)$ and transcript levels of MuRF1 and Atrogin-1 (B). C2C12 myotubes (5 days of differentiation) were cultured in either normoxia or in hypoxia for $48 \mathrm{~h}$. Myotubes were harvested 60 (T60) and 180 (T180) min after IGF-1 addition (20 nM) and analyzed as described in MATERIALS AND METHODS. Myotubes without IGF-1 were used as controls (T0). Values are means \pm SE. aDifferent from T0 in the same culture condition. ${ }^{b}$ Different from the same time point in normoxia. tional area by $11 \%$ (46). ExTr also increased muscle fiber capillarization in skeletal muscle of normoxemic patients. By contrast, skeletal muscle of hypoxemic patients was refractory to the effects of ExTr because both muscle fiber cross-sectional area and capillarization remained unchanged in response to ExTr. Taken together, these data suggest that ExTr increases oxygen delivery in normoxemic patients above the capacity of hypoxemic patients. Interestingly, Vogiatzis et al. (45) previously reported a lower degree of muscle fiber hypertrophy in cachectic patients with COPD compared with noncachectic patients in response to ExTr. Therefore, a resistance of skeletal muscle to the beneficial effects of ExTr in patients with COPD could be a common feature linked to the severity of the disease either appreciated by the extent of cachexia, or by the degree of hypoxia, or both.

Several hypotheses could be evoked to explain the differential regulation in muscle fiber cross-sectional area between normoxemic and hypoxemic patients with COPD. One may first argue that a difference in muscle fiber type distribution could affect muscle fiber cross-sectional area. However, muscle fiber type distribution was similar in both groups before and after ExTr. Second, this observation could also result from an increase in protein degradation in hypoxemic patients with COPD. In the present study, markers of both ubiquitin-proteasome and autophagy-lysosome pathways were unchanged in response to ExTr. The invasive nature of the muscle biopsy precluded the inclusion of an earlier time point during ExTr, so we cannot rule out the possibility that an adaptive response of both ubiquitin-proteasome and autophagy-lysosome pathways may have occurred earlier during the rehabilitation procedure. Third, the different regulation of the Akt/mTOR signaling pathway between normoxemic and hypoxemic patients with COPD in response to ExTr could also contribute to explaining the increase in muscle fiber cross-sectional area in normoxemic patients.

We do not have definite evidence to assume that hypoxemia impairs the adaptive response of skeletal muscle in patients with COPD, but several arguments suggest that hypoxemia could be involved in the unresponsiveness of hypoxemic patients with COPD. First, we previously showed that chronic hypoxia in rodents and severe hypoxemia in patients with COPD downregulated the Akt/mTOR pathway (18). Second, a short-term hypoxia exposure in healthy volunteers $(3.5 \mathrm{~h})$ has been associated with a blunted muscle protein synthesis in 
response to acute resistance exercise (16). Finally, our in vitro analyses on $\mathrm{C} 2 \mathrm{C} 12$ myotubes showed that hypoxia per se almost completely abolished the response of the Akt/mTOR pathway to IGF-1. The mechanisms that could be involved in hypoxia-induced skeletal muscle resistance to an anabolic stimulus are currently unknown. However, a recent in vitro study indicated that hypoxia reduced the sensitivity of the IGF receptor, leading to a decreased activation of Akt in myoblasts (25). Furthermore, insulin receptor substrate-1 has been shown to be phosphorylated on serine or threonine residues in hypoxia, thus preventing further activation of the pathway $(22,41)$. Whether such a mechanism occurs in vivo in adult skeletal muscle deserves further experiments.

\section{Study Limitations}

The limited number of hypoxemic patients $(n=8)$ is acknowledged as a limitation in our study. The clinical outcome initially designed for the present study was a training effect on maximal power output. The statistical power of analysis indicated that eight patients were necessary to detect a $10-\mathrm{W}$ difference in peak workload with a standard deviation of $6 \mathrm{~W}(\alpha=0.05, \beta=90 \%)$. Recent studies have shown significant training-induced adaptations in muscle fiber crosssectional area and protein phosphorylation (43), as well as gene expression in subgroups of 6 to 10 patients with COPD (33), suggesting that despite the limited number of subjects in the hypoxemic group, this would have been enough to detect muscle adaptations.

Another time point of analysis would have also been very informative to further decipher the kinetic response of intracellular signaling events. However, for a number of ethical reasons essentially linked to the invasive nature of the muscle biopsy, this was not possible. Finally, we do not have definite evidence to assume that hypoxemia impairs the adaptive response of skeletal muscle in patients with COPD. Hypoxemic patients received long-term oxygen therapy for at least 3 mo before inclusion. Furthermore, clinical guidelines recommend adding $\mathrm{O}_{2}$ during ExTr sessions to maintain arterial $\mathrm{O}_{2}$ saturation in the $88 \%$ to $90 \%$ range (28). This was carried out in the present study. Therefore, hypoxemic patients lived and exercised with $\mathrm{O}_{2}$ supplementation, which could minimize the effect of muscle hypoxia.

In conclusion, although hypoxemic patients with COPD retained the capacity to improve their exercise capacity in response to ExTr as much as normoxemic patients did, hypoxemic patients with COPD were resistant to ExTr-induced skeletal muscle adaptations.

\section{ACKNOWLEDGMENTS}

We thank Nadia Charifi for technical assistance. Pulmonary rehabilitation was supervised by Pierre Labeix (PT) and Bernard Januel. We thank CHU Saint Étienne for promoting the study.

This is ClinicalTrials.gov identifier NCT00922857.

\section{GRANTS}

Support for this study was provided by grants from the Ministère de la Santé, France (PHRC program 2004) and from Association Lyonnaise de Logistique Post-hospitalière. F. Costes received a fellowship grant from the European Respiratory Society. H. Gosker was supported by Netherlands Asthma Foundation Award 3.2.05.038.

\section{DISCLOSURES}

No conflicts of interest, financial or otherwise, are declared by the authors.

\section{AUTHOR CONTRIBUTIONS}

F.C. and D.G.F. conception and design of research; F.C., M.D., M.C.K., and J.C. performed experiments; F.C., H.R.G., L.F., M.C.K., J.C., and D.G.F. analyzed data; F.C., H.R.G., L.F., M.D., M.C.K., J.C., and D.G.F. interpreted results of experiments; F.C. prepared figures; F.C. and D.G.F. drafted manuscript; F.C., H.R.G., L.F., M.D., J.C., A.M.S., and D.G.F. edited and revised manuscript; F.C., H.R.G., L.F., M.D., M.C.K., J.C., A.M.S., and D.G.F. approved final version of manuscript.

\section{REFERENCES}

1. Agle DP, Baum GL, Chester EH, Wendt M. Multidiscipline treatment of chronic pulmonary insufficiency. 1 Psychologic aspects of rehabilitation. Psychosom Med 35: 41-49, 1973.

2. Altenburg WA, de Greef MH, ten Hacken NH, Wempe JB. A better response in exercise capacity after pulmonary rehabilitation in more severe COPD patients. Respir Med 106: 694-700, 2012.

3. Amirouche A, Durieux AC, Banzet S, Koulmann N, Bonnefoy R, Mouret C, Bigard X, Peinnequin A, Freyssenet D. Down-regulation of $\mathrm{Akt} / \mathrm{mammalian}$ target of rapamycin signaling pathway in response to myostatin overexpression in skeletal muscle. Endocrinology 150: 286294, 2009.

4. Belman MJ, Brooks LR, Ross DJ, Mohsenifar Z. Variability of breathlessness measurement in patients with chronic obstructive pulmonary disease. Chest 99: 566-571, 1991.

5. Bernard S, LeBlanc P, Whittom F, Carrier G, Jobin J, Belleau R, Maltais F. Peripheral muscle weakness in patients with chronic obstructive pulmonary disease. Am J Respir Crit Care Med 158: 629-634, 1998.

6. Berthon P, Duguez S, Favier FB, Amirouche A, Feasson L, Vico L, Denis C, Freyssenet D. Regulation of ubiquitin-proteasome system, caspase enzyme activities, and extracellular proteinases in rat soleus muscle in response to unloading. Pflugers Arch 454: 625-633, 2007.

7. Bodine SC, Latres E, Baumhueter S, Lai VK, Nunez L, Clarke BA, Poueymirou WT, Panaro FJ, Na E, Dharmarajan K, Pan ZQ, Valenzuela DM, DeChiara TM, Stitt TN, Yancopoulos GD, Glass DJ. Identification of ubiquitin ligases required for skeletal muscle atrophy. Science 294: 1704-1708, 2001.

8. Carone M, Patessio A, Ambrosino N, Baiardi P, Balbi B, Balzano G, Cuomo V, Donner CF, Fracchia C, Nava S, Neri M, Pozzi E, Vitacca M, Spanevello A. Efficacy of pulmonary rehabilitation in chronic respiratory failure (CRF) due to chronic obstructive pulmonary disease (COPD): the Maugeri Study. Respir Med 101: 2447-2453, 2007.

9. Chaudhary P, Suryakumar G, Prasad R, Singh SN, Ali S, Ilavazhagan G. Chronic hypobaric hypoxia mediated skeletal muscle atrophy: role of ubiquitin-proteasome pathway and calpains. Mol Cell Biochem 364: 101113, 2012.

10. Desgeorges MM, Freyssenet D, Chanon S, Castells J, Pugnière P, Béchet D, Peinnequin A, Devillard X, Defour A. Post-transcriptional regulation of autophagy in $\mathrm{C} 2 \mathrm{C} 12$ myotubes following starvation and nutrient restoration. Int J Biochem Cell Biol 54: 208-216, 2014.

11. Doucet M, Russell AP, Léger B, Debigaré R, Joanisse DR, Caron MA, LeBlanc P, Maltais F. Muscle atrophy and hypertrophy signaling in patients with chronic obstructive pulmonary disease. Am J Respir Crit Care Med 176: 261-269, 2007.

12. Duguez S, Bihan Le MC, Gouttefangeas D, Féasson L, Freyssenet D. Myogenic and nonmyogenic cells differentially express proteinases, Hsc/ Hsp70, and BAG-1 during skeletal muscle regeneration. Am J Physiol Endocrinol Metab 285: E206-E215, 2003.

13. Duguez S, Féasson L, Denis C, Freyssenet D. Mitochondrial biogenesis during skeletal muscle regeneration. Am J Physiol Endocrinol Metab 282: E802-E809, 2002.

14. Durieux AC, Amirouche A, Banzet S, Koulmann N, Bonnefoy R, Pasdeloup M, Mouret C, Bigard X, Peinnequin A, Freyssenet D. Ectopic expression of myostatin induces atrophy of adult skeletal muscle by decreasing muscle gene expression. Endocrinology 148: 3140-3147, 2007.

15. Eliason G, Abdel-Halim SM, Piehl-Aulin K, Kadi F. Alterations in the muscle-to-capillary interface in patients with different degrees of chronic obstructive pulmonary disease. Respir Res 11: 97, 2010.

16. Etheridge T, Atherton PJ, Wilkinson D, Selby A, Rankin D, Webborn N, Smith K, Watt PW. Effects of hypoxia on muscle protein synthesis (MPS) and anabolic signaling at rest and in response to acute resistance exercise. Am J Physiol Endocrinol Metab 301: E697-E702, 2011. 
17. Fabbri LM, Rabe KF. From COPD to chronic systemic inflammatory syndrome? Lancet 370: 797-799, 2007.

18. Favier FB, Costes F, Defour A, Bonnefoy R, Lefai E, Bauge S, Peinnequin A, Benoit H, Freyssenet DG, Baugé S. Downregulation of Akt/mammalian target of rapamycin pathway in skeletal muscle is associated with increased REDD1 expression in response to chronic hypoxia. Am J Physiol Regul Integr Comp Physiol 298: R1659-R1666, 2010.

19. Hepple RT, Mackinnon SL, Goodman JM, Thomas SG, Plyley MJ. Resistance and aerobic training in older men: effects on $\dot{\mathrm{V}}_{2}$ peak and the capillary supply to skeletal muscle. J Appl Physiol 82: 1305-1310, 1997.

20. Howald H, Pette D, Simoneau JA, Uber A, Hoppeler H, Cerretelli P. Effects of chronic hypoxia on muscle enzyme activities. Int J Sport Med 11: S10-S14, 1990

21. Joassard OR, Amirouche A, Gallot YS, Desgeorges MM, Castells J, Durieux AC, Berthon P, Freyssenet DG. Regulation of Akt-mTOR, ubiquitin-proteasome and autophagy-lysosome pathways in response to formoterol administration in rat skeletal muscle. Int J Biochem Cell Biol 45: 2444-2455, 2013.

22. Kang SG, Brown AL, Chung JH. Oxygen tension regulates the stability of insulin receptor substrate-1 (IRS-1) through caspase-mediated cleavage. J Biol Chem 282: 6090-6097, 2007.

23. Kyle UG, Dupertuis YM, Raguso CA, Hans D, Pichard C. Appendicular skeletal muscle mass (ASMM) percentiles in 7489 healthy adults aged 18-98 years determined by bioelectrical impedance analysis (BIA). Clin Nutr 22: S1, 2003

24. Lewis MI, Fournier M, Storer TW, Bhasin S, Porszasz J, Ren SG, Da $\mathbf{X}$, Casaburi R. Skeletal muscle adaptations to testosterone and resistance training in men with COPD. J Appl Physiol 103: 1299-1310, 2007.

25. Majmundar AJ, Skuli N, Mesquita RC, Kim MN, Yodh AG, NguyenMcCarty M, Simon MC. O(2) regulates skeletal muscle progenitor differentiation through phosphatidylinositol 3-kinase/AKT signaling. Mol Cell Biol 32: 36-49, 2012.

26. Mammucari C, Milan G, Romanello V, Masiero E, Rudolf R, Del Piccolo P, Burden SJ, Di Lisi R, Sandri C, Zhao J, Goldberg AL, Schiaffino S, Sandri M. FoxO3 controls autophagy in skeletal muscle in vivo. Cell Metab 6: 458-471, 2007.

27. McClelland GB, Brooks GA. Changes in MCT 1, MCT 4, and LDH expression are tissue specific in rats after long-term hypobaric hypoxia. $J$ Appl Physiol 92: 1573-1584, 2002.

28. Nici L, Donner C, Wouters E, Zuwallack R, Ambrosino N, Bourbeau J, Carone M, Celli B, Engelen M, Fahy B, Garvey C, Goldstein R, Gosselink R, Lareau S, MacIntyre N, Maltais F, Morgan M, O'Donnell D, Prefault C, Reardon J, Rochester C, Schols A, Singh S, Troosters T. American Thoracic Society/European Respiratory Society statement on pulmonary rehabilitation. Am J Respir Crit Care Med 173: $1390-1413,2006$

29. Pison CM, Cano NJ, Chérion C, Caron F, Court-Fortune I, Antonini MT, Gonzalez-Bermejo J, Meziane L, Molano LC, Janssens JP, Costes F, Wuyam B, Similowski T, Melloni B, Hayot M, Augustin J, Tardif C, Lejeune H, Roth H, Pichard C. Multimodal nutritional rehabilitation improves clinical outcomes of malnourished patients with chronic respiratory failure: a randomised controlled trial. Thorax 66: 953-960, 2011.

30. Plant PJ, Brooks D, Faughnan M, Bayley T, Bain J, Singer L, Correa J, Pearce D, Binnie M, Batt J. Cellular markers of muscle atrophy in chronic obstructive pulmonary disease. Am J Respir Cell Mol Biol 42: 461-471, 2010.

31. Puhan MA, Chandra D, Mosenifar Z, Ries A, Make B, Hansel NN, Wise RA, Sciurba F. The minimal important difference of exercise tests in severe COPD. Eur Respir J 37: 784-790, 2011.

32. Rabe KF, Hurd S, Anzueto A, Barnes PJ, Buist SA, Calverley P, Fukuchi Y, Jenkins C, Rodriguez-Roisin R, van Weel C, Zielinski J. Global strategy for the diagnosis, management, and prevention of chronic obstructive pulmonary disease: GOLD executive summary. Am J Respir Crit Care Med 176: 532-555, 2007.

33. Radom-Aizik S, Kaminski N, Hayek S, Halkin H, Cooper DM, BenDov I. Effects of exercise training on quadriceps muscle gene expression in chronic obstructive pulmonary disease. J Appl Physiol 102: 1976-1984, 2007.

34. Ries AL, Bauldoff GS, Carlin BW, Casaburi R, Emery CF, Mahler DA, Make B, Rochester CL, Zuwallack R, Herrerias C. Pulmonary rehabilitation: joint ACCP/AACVPR evidence-based clinical practice guidelines. Chest 131: 4S-42S, 2007.

35. Ripamonti M, Viganò A, Moriggi M, Milano G, von Segesser LK, Samaja M, Gelfi C. Cytochrome c oxidase expression in chronic and intermittent hypoxia rat gastrocnemius muscle quantitated by $\mathrm{CE}$. Electrophoresis 27: 3897-3903, 2006.

36. Rommel C, Bodine SC, Clarke BA, Rossman R, Nunez L, Stitt TN, Yancopoulos GD, Glass DJ. Mediation of IGF-1-induced skeletal myotube hypertrophy by $\mathrm{PI}(3) \mathrm{K} / \mathrm{Akt} / \mathrm{mTOR}$ and $\mathrm{PI}(3) \mathrm{K} / \mathrm{Akt} / \mathrm{GSK} 3$ pathways. Nat Cell Biol 3: 1009-1013, 2001.

37. Sandri M, Sandri C, Gilbert A, Skurk C, Calabria E, Picard A, Walsh K, Schiaffino S, Lecker SH, Goldberg AL. Foxo transcription factors induce the atrophy-related ubiquitin ligase atrogin-1 and cause skeletal muscle atrophy. Cell 117: 399-412, 2004.

38. Schols AM, Broekhuizen R, Weling-Scheepers CA, Wouters EF. Body composition and mortality in chronic obstructive pulmonary disease. Am J Clin Nutr 82: 53-59, 2005.

39. Schols AM, Soeters PB, Mostert R, Pluymers RJ, Wouters EF. Physiologic effects of nutritional support and anabolic steroids in patients with chronic obstructive pulmonary disease. A placebo-controlled randomized trial. Am J Respir Crit Care Med 152: 1268-1274, 1995.

40. Stitt TN, Drujan D, Clarke BA, Panaro F, Timofeyva Y, Kline WO, Gonzalez M, Yancopoulos GD, Glass DJ. The IGF-1/PI3K/Akt pathway prevents expression of muscle atrophy-induced ubiquitin ligases by inhibiting FOXO transcription factors. Mol Cell 14: 395-403, 2004.

41. Tzatsos A, Tsichlis PN. Energy depletion inhibits phosphatidylinositol 3-kinase/Akt signaling and induces apoptosis via AMP-activated protein kinase-dependent phosphorylation of IRS-1 at Ser-794. J Biol Chem 282: 18069-18082, 2007

42. Vallet G, Ahmaïdi S, Serres I, Fabre C, Bourgouin D, Desplan J, Varray A, Préfaut C. Comparison of two training programmes in chronic airway limitation patients: standardized versus individualized protocols. Eur Respir J 10: 114-122, 1997.

43. Vandesompele J, De Preter K, Pattyn F, Poppe B, Van Roy N, De Paepe A, Speleman F. Accurate normalization of real-time quantitative RT-PCR data by geometric averaging of multiple internal control genes. Genome Biol 3: 1-12, 2002.

44. Vincent L, Féasson L, Oyono-Enguéllé S, Banimbek V, Denis C, Guarneri C, Aufradet E, Monchanin G, Martin C, Gozal D, Dohbobga M, Wouassi D, Garet M, Thiriet P, Messonnier L. Remodeling of skeletal muscle microvasculature in sickle cell trait and alpha-thalassemia. Am J Physiol Heart Circ Physiol 298: H375-H384, 2010.

45. Vogiatzis I, Simoes DC, Stratakos G, Kourepini E, Terzis G, Manta P, Athanasopoulos D, Roussos C, Wagner PD, Zakynthinos S. Effect of pulmonary rehabilitation on muscle remodelling in cachectic patients with COPD. Eur Respir J 36: 301-310, 2010.

46. Vogiatzis I, Terzis G, Stratakos G, Cherouveim E, Athanasopoulos D, Spetsioti S, Nasis I, Manta P, Roussos C, Zakynthinos S. Effect of pulmonary rehabilitation on peripheral muscle fiber remodeling in patients with COPD in GOLD stages II to IV. Chest 140: 744-752, 2011.

47. Wagner PD. Possible mechanisms underlying the development of cachexia in COPD. Eur Respir J 31: 492-501, 2008

48. Wanger J, Clausen JL, Coates A, Pedersen OF, Brusasco V, Burgos F, Casaburi R, Crapo R, Enright P, van der Grinten CP, Gustafsson P, Hankinson J, Jensen R, Johnson D, Macintyre N, McKay R, Miller MR, Navajas D, Pellegrino R, Viegi G. Standardisation of the measurement of lung volumes. Eur Respir J 26: 511-522, 2005.

49. Wüst RC, Degens H. Factors contributing to muscle wasting and dysfunction in COPD patients. Int J Chron Obstruct Pulmon Dis 2: 289-300, 2007.

50. Zhao J, Brault JJ, Schild A, Cao P, Sandri M, Schiaffino S, Lecker SH, Goldberg AL. FoxO3 coordinately activates protein degradation by the autophagic/lysosomal and proteasomal pathways in atrophying muscle cells. Cell Metab 6: 472-483, 2007. 